\title{
Evaluation of antibacterial effect of some Sinai medicinal plant extracts on bacteria isolated from bovine mastitis
}

\author{
Gamil S. G. Zeedan ${ }^{1}$, Abeer M. Abdalhamed ${ }^{1}$, Eman Abdeen², Mahmoud E. Ottai ${ }^{3}$ and Sobhy Abdel-Shafy ${ }^{1}$
}

1. Department of Parasitology and Animal Diseases, Veterinary Research Division, National Research Center, Dokki, Giza, Egypt; 2. Department of Bacteriology, Immunology and Mycology, Faculty of Veterinary Medicine, University of Sadat City, Monifia, Egypt; 3. Department of Genetics and Cytology, Genetic Engineering and Biotechnology Division, National Research Center, Dokki, Giza, Egypt.

Corresponding author: Gamil S. G. Zeedan, e-mail: gamilzee@yahoo.com, AMA: abeerg2007@yahoo.com, EA: eman abdeen79@yahoo.com, MEO: mohmoud ottai@yahoo.com, SAS: aasobhy@yahoo.com Received: 21-07-2014, Revised: 15-10-2014, Accepted: 22-10-2014, Published online: 27-11-2014

doi: 10.14202/vetworld.2014.991-998. How to cite this article: Zeedan GSG, Abdalhamed AM, Abdeen E, Ottai ME, Abdel-Shafy S (2014) Evaluation of antibacterial effect of some Sinai medicinal plant extracts on bacteria isolated from bovine mastitis, Veterinary World, 7(11): 991-998.

\begin{abstract}
Aim: Bovine mastitis is the most economically important disease affecting dairy cattle worldwide from an economic, diagnostic and public-health point of view. The present study aimed to isolate and identify of bacteria causes mastitis in dairy cows and to evaluate the antibacterial activities of some selected medicinal plants extracts comparing antibiotics used in the treatment of mastitis in Egypt.

Materials and Methods: A total of 203 milk samples of dairy cows were collected during the period from February to June 2013 at different Governorates in Egypt. The use clinical inspection and California mastitis test examination were provided efficient diagnostic tool for detection of clinical, subclinical mastitis and apparently normal health cattle. The collected milk samples were cultured on Nutrient, Blood agar, Mannitol salt, Edward's and MacConkey agar plates supporting the growth of various types of bacteria for their biochemical studies and isolation. The antimicrobial activity of plants extracts (Jasonia montana and Artemisia herb alba)with different solvent (ethanol, petroleum ether, chloroform and acetone)were studied in vitro against isolated bacteria from mastitis by paper desk diffusion and minimum inhibitory concentration method (MIC).

Results: The prevalence of clinical, subclinical mastitis and normal healthy animals were 34.50\%, 24.7\% and 40.8\% respectively. The major pathogens isolated from collected milk samples were Escherichia coli (22.16\%), Staphylococcus aureus (20.19\%), Streptococcus spp. (13.3\%), Streptococcus agalactiae (12.8\%), Streptococcus dysgalactia (0.5\%), Pasteurella spp. (2.45\%), Klebsiella spp. (1.47\%)and Pseudomonas spp. (0.45\%). The highest antibacterial activity of $J$. montana plant extracted with acetone solvent against S. agalactiae, E. coli, S. aureus, Klebsiella spp and coagulase-negative Staphylococci with zone of inhibition values \pm standard deviation (SD), ranging from $4.33 \pm 0.57$ to $25.6 \pm 0.60 \mathrm{~mm}$. The MIC values for the extracts ranged from 0.01 to $1.56 \mathrm{mg} / \mathrm{ml}$. when comparing antibacterial activity of $A$. herb alba plant extracted with acetone solvent on the same bacteria with zone of inhibition values $\pm \mathrm{SD}$, ranging from $00 \pm 00$ to $5.6 \pm 0.60 \mathrm{~mm}$. Both extracts from $J$. montana and A. herb alba plant extracts with petroleum ether, methanol and chloroform solvent were less antibacterial activities than acetone solvent extract.

Conclusion: The present study spot highlight on isolation and identification of mastitis pathogens that are fundamental aspects of milk quality, udder health control programs and public health and food safety issues associated with food borne pathogens. J. montana and A. herb alba plants have antibacterial effects more than antibiotics used in the treatment of mastitis. Finally, the medicinal plant extracts can be used to discover bioactive natural product in the form of antibacterial that may be serve the development of new pharmaceutical products. But still need further research necessary to identify active compounds and research to mechanism and drug interaction.
\end{abstract}

Keywords: antimicrobial agent, Artemisia herb alba, California mastitis test, Jasonia montana, minimum inhibitory concentration.

\section{I ntroduction}

Mastitis, inflammation of the mammary gland, is a costly production disease affecting the dairy cattle industry worldwide [1,2]. It causes a fall in milk production, decreased milk quality, economic diagnostic and it's considered of quite vital importance to the public health due to its association with many zoonotic diseases in which the milk act as a vehicle for some infectious agents [3]. The most common mastitis

Copyright: The authors. This article is an open access article licensed under the terms of the Creative Commons Attributin License (http:// creative commons.org/licenses/by/2.0) which permits unrestricted use, distribution and reproduction in any medium, provided the work is properly cited. pathogens are caused by a wide variety of bacteria, which can be classified as environmental (Escherichia coli, Streptococcus dysgalactiae, Streptococcus uberis, Enterococcus spp. and coagulase-negative Staphylococci [CNS]) or contagious (Staphylococcus aureus and Streptococcus agalactiae) [4]. Contagious mastitis pathogens are generally transmitted from cow to cow [5]. The infection is transmitted by milk-contaminated fomites at milking, by the Milker's hands, or by the milking machine. Environmental mastitis transmission by contact of the teats with contaminated soil, bedding and water with faecal materials [6,7]. Many bacteria strains are resistant to one or more antibiotics used in treatment bovine mastitis [8]. The increasingly 
growing rate of antibiotic resistance to microorganisms necessitates the developed and search of new antimicrobial agents to combat this problem. Medicinal plant-derived compounds have increased widespread interest in the search of alternative antibacterial agents because of the perception that they are safe and have a long history of use in folk medicine for the treatment of infectious diseases $[7,8]$. Natural products of higher plants may possess a new source of antimicrobial agents with possibly novel mechanisms of action [9]. Medicinal plants are rich in a wide variety of secondary metabolites such as tannins, alkaloids and flavonoids, which have been found in vitro to have antimicrobial properties [10,11]. A number of phyotherapy manuals mentioned that the various natural plants able to treat infectious diseases, fewer side effects and low toxicity $[12,13]$. There are several reports on the antimicrobial activity of different herbal extracts [14]. Many herbal plants have been found to cure gastrointestinal disorders, respiratory diseases and cutaneous infections [15]. Artemisia herb-alba plant is known as desert wormwood (known in Arabic as shih)[16,17], it has been used in folk medicine to treat arterial hypertension and/or diabetes [18]. Herbal tea from this species has been used as analgesic, antibacterial, antispasmodic, and haemostatic agents [19]. Jasonia montana belongs to family Asteraceae, growing in the mediterranean and adjacent areas, including the Sinai Peninsula, Egypt and in Arabic known Nohida [20]. This herb has a strong aromatic odor and is used in traditional medicine for diarrhea, stomach ache, chest diseases and the different plant extracts as hypoglycemic and antioxidant. But there are no reports of the antibacterial effects on multidrug resistant bacteria.

In Egypt, A. herb alba and J. montana plants are common used in folk medicine as herbal tea for the treatment of renal troubles [20]. Many reports in the literature confirmed that $J$. montana is rich in methoxylated flavonoids that have a cytotoxic activity against carcinogenic cells [21]. The present work aims to isolate and identify microorganisms causing bovine mastitis and evaluate the antibacterial activity of selected some Sinai medicinal plant extracts against bacteria isolated from bovine mastitis.

\section{Materials and Methods}

\section{Ethical approval}

Approval was taken from the ethical committee of National Research Center, Giza, Egypt for collection of milk samples by describing the protocols of the study. After explanation of the study objective. The study was conducted during the period between February and June 2013. Milk samples were taken by a veterinarian in all examined animals at Beni-Suef, El-Fayoum, Behera and Monofia Governorates in Egypt.

\section{Milk samples}

A total of 203 samples (70 clinical and 50 subclinical cases of mastitis and 83 normal healthy)were collected from individuals dairy cows at Beni-Suef, El-Fayoum, Behera and Monofia Governorates in Egypt during the period between February and June 2013. Milk samples were taken by a veterinarian in all examined animals. The bacterial culture medium was prepared in the laboratory as per standard procedures.

\section{California mastitis test (CMT)}

The CMT was conducted to diagnose the presence of subclinical mastitis and it was carried out according to procedures given by Quinn et al. [22]. A few drops of milk from each quarter of the udder was placed in each of four cups in the CMT paddle and an equal amount of the reagent was added. A gentle circular motion was applied. Positive samples show gel formation within a few seconds. The result was scored based on the gel formation positive and negative, cow was considered mastitic if one or more quarters were CMT positive.

\section{Bacterial isolation and identification}

A loop full from fresh and incubated milk was streaked onto plates of nutrient agar, blood agar, mannitol salt agar, Edward's and MacConkey agar media and incubated at $37^{\circ} \mathrm{C}$ for $24-48 \mathrm{~h}$. Suspected colonies were picked up and examined microscopically in gram stained films before being transferred in semisolid agar to be subjected for further identification of pathogens including gram's staining technique and catalase test to distinguish between Streptococci and Staphylococci. The hemolytic patterns and coagulase reaction with rabbit plasma were used to differentiated between $S$. aureus and CNS. Also, esculin hydrolysis and Christie-Atkins, Munch-Petersen (CAMP) reaction differentiated between $S$. agalactiae and other Streptococcus spp. [23]. Gram-negative bacteria were identified by sub culturing on differential and selective media and tested to oxidase activity, acid production (glucose, lactose and sucrose fermentation), indole test, Voges-Proskauer test (VP) and hydrogen sulfide production as National Mastitis Council's guidelines [24]. Api-20E system (analytical profile index, BioMerieux) used for confirmation the bacterial isolates according to instructions of the manufacture.

\section{Medicinal plants}

The aerial parts (steams, leaves and flowers) of A. herba alba and J. montana plants were collected from Saint Catherine, South Sinai, Egypt in January 2014. The plants were performed by a group of genetics and breeding of medicinal and aromatic plants. Department of Genetics and Cytology, Genetic Engineering and Biotechnology Division, National Research Center, Cairo, Egypt. Washed with distilled water, dried in the shade and stored in airtight containers at room temperature in dark until used.

\section{Preparation of plant extracts}

The aerial parts (steams, leaves and flowers) samples from plants were subjected to extraction by the method described by AOAC [25]. Successive extractions for aerial parts were carried out using four 
ascending polar solvents: Petroleum ether, chloroform, acetone and ethanol. $100 \mathrm{~g}$ of aerial parts was placed in a soxhlet apparatus containing petroleum ether and left for $12 \mathrm{~h}$, then recycled for $6 \mathrm{~h}$ until full clearance. The mace was left for dryness after the exhaustive extraction with petroleum ether, then repacked in the soxhlet apparatus and successively extracted with chloroform, followed by acetone and ethanol. All the extracts were dried by distilling off the solvents under pressure using a rotary evaporator [25].

\section{Antimicrobial plant extracts assays}

\section{Modified disc diffusion method}

Antimicrobial plant extracts activity methods were done as the guidelines of National Committee for Clinical Laboratory Standards [26,27]. MuellerHinton Agar was prepared as the manufacturer's instructions and checked for sterility by incubating the plates overnight at $37^{\circ} \mathrm{C}$. Modified discs of $6 \mathrm{~mm}$ were prepared using a Whitman filter paper. 100 discs were obtained by punching and putting in vials-bottles and sterilizing in an oven at $170^{\circ} \mathrm{C}$ for $30 \mathrm{~min}$. The discs were impregnating with $20 \mu \mathrm{l}$ of plant extract (concentration $200 \mathrm{mg} / \mathrm{ml}$ ). The discs were evaporated at $37^{\circ} \mathrm{C}$ for $24 \mathrm{~h}$. Prepared discs containing the various extracts were carefully placed on the inoculated plates using a sterilized forceps in each disk according to Wiegand et al. [28]. The disc with solvent alone as negative control one and antibiotic discs were the positive controls. The plates were then turned upsidedown and incubated at $37^{\circ} \mathrm{C}$ for $24 \mathrm{~h}$ in an incubator. The results were taken by considering the zone of growth and inhibition of the organisms by the test fractions. Antimicrobial activity was evaluated by measuring the diameter of the inhibition zone (DIZ) around the disc as mean \pm standard deviation (SD).

\section{Minimum inhibitory concentration (MIC) of plant extracts using micro dilution method}

MIC was determined by micro dilution technique as described by the National Committee for Clinical Laboratories standards [29]. The MIC was defined as the lowest concentration of the compound to inhibit the growth of microorganism. The 96-well plates were prepared by dispensing $50 \mu \mathrm{l}$ of Mueller-Hinton broth for bacteria, into each well. A $50 \mu \mathrm{l}$ from the stock solution of tested extracts (concentration of $200 \mathrm{mg} / \mathrm{ml}$ ) was added into the first row of the plate. Then, two-fold, serial dilutions were performed by using a micropipette. The obtained concentration range from 100 to $0.195 \mathrm{mg} / \mathrm{ml}$, and then added $10 \mu \mathrm{l}$ of inocula to each well except a positive control (inoculums were adjusted to contain approximately $1 \times 10^{8} \mathrm{CFU} / \mathrm{ml}$. Plant extract with media was used as a positive control and inoculums with media was used as a negative control. Micro titer plates were incubated at $37^{\circ} \mathrm{C}$ for $24 \mathrm{~h}$. Lack of turbidity was further confirmed by pouring suspension aliquot of $0.1 \mathrm{ml}$ into pre-sterilized petri dishes with nutrient agar medium. The tests were conducted in triplicate.

\section{Statistical analysis}

All data were subjected to statistical analysis including the calculation of the mean and SD. Significance between data of control and infected groups was evaluated by the Student's $t$-test at $\mathrm{p}<0.05$ according to Petrie and Watson [30] using SPSS for windows version 15 (SPSS, Chicago, IL, 2006) computer program.

\section{Results}

The results showed that the quarter was considered sub-clinically affected when positively by CMT. A total of 203 milk samples were screened for mastitis by CMT. The prevalence of clinical, subclinical mastitis and normal healthy animals were 34.58\%, 24.7\% and $40.8 \%$ respectively. Out of 203 cow's milk samples 171 isolates were obtained from 83 normal healthy, 70 clinical and 50 subclinical cases of mastitis at Benisuef, El-Fayoum, Behera and Monofia Governorates in Egypt. Major bacterial isolates were E. coli (22.16\%), S. aureus (20.19\%), Streptococcus spp. (13.30\%), Pasteurella spp. (2.45\%), Klebsiella spp. (1.47\%)and Pseudomonas spp. (0.5\%) (Table-1 and Figure-1).

Gram-positive and catalase test positive distinguished between Streptococci and Staphylococci. The hemolytic patterns and coagulase reaction with rabbit plasma were used to differentiated between $S$. aureus and CNS. Also, esculin hydrolysis and CAMP reaction differentiated between S. agalactia and another strep. Gram-negative bacteria were identify by sub culturing on differential and selective media and tested to oxidase activity, acid production (glucose, lactose and sucrose fermentation), indole test, VP test and hydrogen sulfide production as National Mastitis Council's guidelines as in Table- 2 and Figure-2.

Confirmation test for E. coli with Api-20E0 test. The result of Api-E20 test was revealed the numerical profile [5144552] as confirmed diagnostic test for E. coli isolates.

\section{Antibacterial susceptibility test}

The antibiogram profile of different bacterial isolates indicated that the antibiotic enrofloxacin, oxtetracycline and ampecillin showed different activity compared with plant extracts on isolated. There was significant variation in the antibacterial activities of $J$. montana and $A$. herb alba plant extracts that have antibacterial effect on Gram-positive isolated bacteria, the highest activity were observed with acetone extracts of J. montana compared to A. herb alba on Gram-positive bacteria S. aureus, Sterptococcus spp., S. agalactiae and CNS with DIZ values in range of $25.6 \pm 0.60$ and $20.66 \pm 0.57,18.67 \pm 0.57$ and $19.66 \pm 0.58 \mathrm{~mm}$ respectively. The petroleum ether, methanol and chloroform extracts of $J$. montana have shown less antibacterial activity (Table-3). The most effective antibacterial activity was recorded for $J$. montana which has inhibited S. aureus, Sterptococcus spp., S. agalactiae and CNS (DIZ 25.6 $\pm 0.57,20.66 \pm 0.5$ and $19.6 \pm 0.56 \mathrm{~mm}$ ). The second highest antibacterial activity was A. herb alba that recorded a DIZ range between $6.33 \pm 0.57$ 


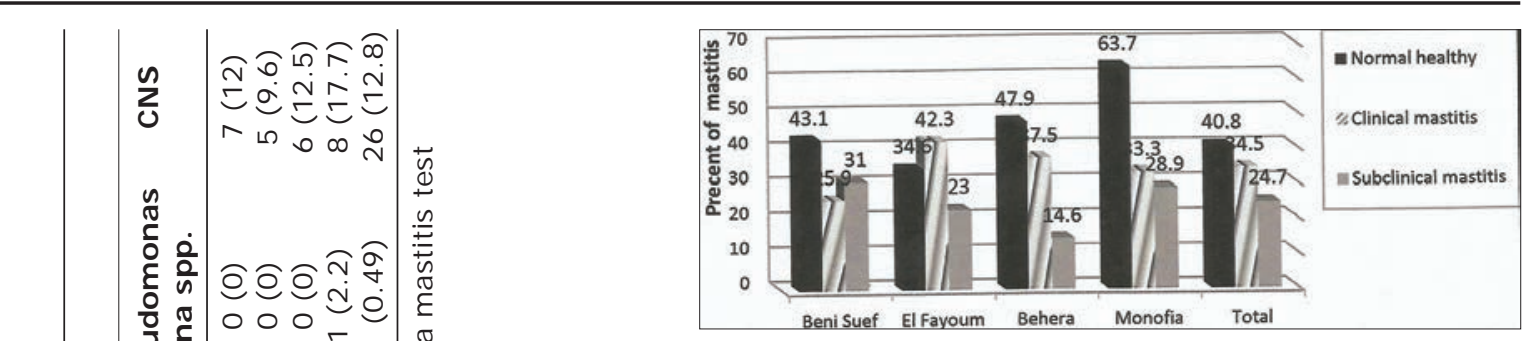

Figure-1: Prevalence of clinical and subclinical mastitis at different Governorates in Egypt.

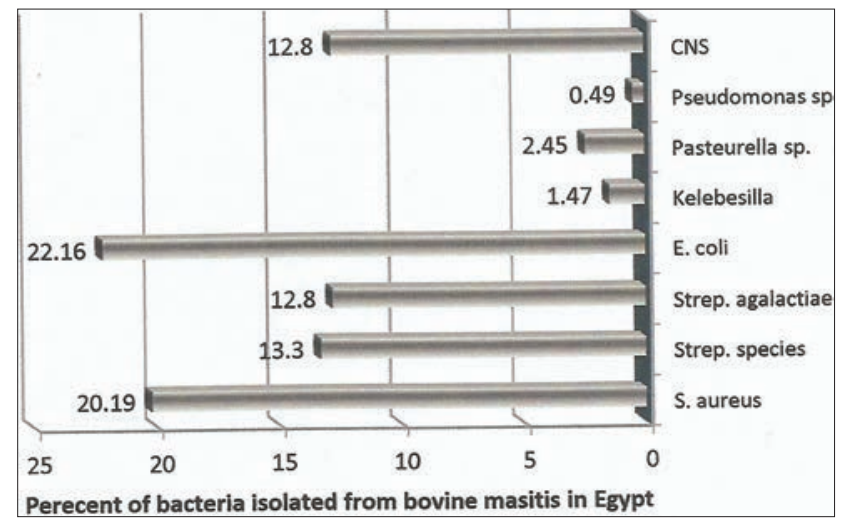

Figure-2: Percentage of isolated bacteria from bovine mastitis in Egypt.

and $9.67 \pm 0.57 \mathrm{~mm}$. The highest antibacterial effect was recorded for $S$. aureus $(9.67 \pm 0.58 \mathrm{~mm})$. This difference was significant $(\mathrm{p}<0.05)$ statistically as in Table-3. Evaluation of antibacterial activity (MIC) was carried out by micro dilution method for methanol, petroleum ether, acetone and chloroform extracts of J. montana and A. herb alba on Gram-positive bacteria S. aureus, Sterptococcus spp. The MIC value of $J$. montana was found by acetone extracts leaves gave the best antibacterial activity against Gram-positive bacteria. This activity may be attributed to the rich plant contents of active components such as alkaloids and flavonoides. The MIC for A. herb-alba leaves extracts against Gram-positive bacteria particularly was found to be significantly active exhibiting the little potency with all solvents used and this confirms of the need for further studied. Comparing plant extracts with enrofloxacin antibiotic showed antimicrobials against bacteria causing mastitis as in Figures-3a-c.

The results of antibacterial activity of plant extracts were recorded as presence or absence of zones of inhibition around the discs indicated the absence of microbial growth and it as reported as positive and absence of zone as negative antibacterial activity by referring the measurement to a chart, the organisms classified to susceptible (S) as in Figure-4a (1,3,4 and 6) inhibition around the discs or resistant (R) as in (2 and 5) no inhibition zone around the disk. Figure-4b susceptible (S) as in (4 and 6) or resistant (R) as in (5).

\section{Discussion}

Mastitis in dairy cows is a serious problem as it is an economically devastating disease causing immense 
Table-2: Biochemical characteristics of isolated bacteria from bovine mastitis.

\begin{tabular}{lcccccccccccc}
\hline Gram stain & TSI & Man & Mot & In & MR & VP & Cit & Ur & Oxi & Cat & H2S & I dentification isolated \\
\hline G-ve & - & Acid & + & + & + & - & - & - & - & - & - & E. coli \\
G-ve & + & Acid & - & - & - & + & + & + & - & - & & Kebesilla spp. \\
G-ve & + & Acid & + & - & + & - & - & + & + & + & - & Pseudomonas spp. \\
\hline
\end{tabular}

$+=$ Positive reaction, $-=$ Negative reaction, TSI=Triple sugar iron, Man=Mannitol, Mot=Motility, $|\mathrm{n}=|$ ndole, $M R=$ Methyl red, $\mathrm{VP}=$ Voges-Proskaeur, Cit=Citrate, Ur-Urease, Oxi=Oxidase; Cat=Catalase, $\mathrm{H}_{2} \mathrm{~S}=$ Hydrogen sulphide

Table-3: Antimicrobial activity of A. herb alba and J. montana extracted by different chemical solvents on bacteria isolated from bovine mastitis by disk diffusion method (values were calculated as means of triplicates).

\begin{tabular}{|c|c|c|c|c|c|c|}
\hline \multirow[t]{2}{*}{ Plant extract } & \multicolumn{6}{|c|}{ DIZ (mean $\pm S D)$} \\
\hline & E. coli & S. aureus & Streptococcus spp. & S. agalactia & Pseudomonas spp. & CNS \\
\hline \multicolumn{7}{|l|}{ A. herb alba } \\
\hline Petroleum ether & $2.66 \pm 0.57^{\circledR}$ & $6.30 \pm 0.58$ & $7.67 \pm 0.57$ & $6.30 \pm 0.60$ & $2.66 \pm 0.50^{\circledR}$ & $8.33 \pm 0.58$ \\
\hline Methanol & $3.33 \pm 0.50^{\circledR}$ & $9.67 \pm 0.58$ & $1.00 \pm 0.00^{\circledR}$ & $8.67 \pm 0.58$ & $3.57 \pm 0.57^{\circledR}$ & $1.00 \pm 0.00^{\circledR}$ \\
\hline Chloroform & $1.00 \pm 0.00^{\circledR}$ & $6.3 \pm 0.60$ & $6.30 \pm 0.60$ & $5.66 \pm 0.57$ & $1.00 \pm 0.00^{\circledR}$ & $7.00 \pm 0.57$ \\
\hline Acetone & $0.00 \pm 0.0^{\circledR}$ & $4.66 \pm 0.57^{\circledR}$ & $4.37 \pm 0.58$ & $4.33 \pm 0.57^{\circledR}$ & $0.00 \pm 0.00^{\circledR}$ & $5.66 \pm 0.57$ \\
\hline \multicolumn{7}{|l|}{ J. montana } \\
\hline Petroleum ether & $1.00 \pm 0.00^{\circledR}$ & $2.66 \pm 0.57^{\circledR}$ & $2.57 \pm 0.60^{\circledR}$ & $3.67 \pm 0.50$ & $1.00 \pm 0.00^{\circledR}$ & $2.66 \pm 0.50^{\circledR}$ \\
\hline Methanol & $3.66 \pm 0.5^{\circledR}$ & $6.30 \pm 0.60$ & $4.66 \pm 0.57^{\circledR}$ & $8.66 \pm 0.58$ & $2.66 \pm 0.57^{\circledR}$ & $4.33 \pm 0.57^{\circledR}$ \\
\hline Chloroform & $1.00 \pm 0.0^{\circledR}$ & $4.33 \pm 0.54$ & $4.33 \pm 0.6$ & $4.33 \pm 0.60^{\circledR}$ & $0.00 \pm 0.00^{\circledR}$ & $5.57 \pm 0.54$ \\
\hline Acetone & $4.66 \pm 0.57^{\circledR}$ & $25.60 \pm 0.59^{s}$ & $20.66 \pm 0.59^{5+}$ & $18.67 \pm 0.57^{5+}$ & $3.57 \pm 0.0 .57^{\circledR}$ & $19.66 \pm 0.58^{S+}$ \\
\hline \multicolumn{7}{|l|}{ Antibiotics } \\
\hline Enrofloxacin & $11.66 \pm 0.60^{s+}$ & $9.67 \pm 0.58$ & $9.67 \pm 0.57$ & $9.67 \pm 0.57$ & $7.67 \pm 0.57$ & $9.67 \pm 0.58$ \\
\hline Oxytetracyline & $2.33 \pm 0.58^{\circledR}$ & $7.67 \pm 0.58$ & $8.33 \pm 0.58$ & $8.33 \pm 0.58$ & $4.66 \pm 0.58^{\circledR}$ & $7.67 \pm 0.58$ \\
\hline Ampecillin & $0.00 \pm 0.00^{\circledR}$ & $3.66 \pm 0.50^{\circledR}$ & $3.33 \pm 0.58^{\circledR}$ & $3.33 \pm 0.58^{\circledR}$ & $0.00 \pm 0.00^{\circledR}$ & $3.67 \pm 0.550^{\circledR}$ \\
\hline
\end{tabular}

${ }^{\circledR}$ Resistant (small inhibition zone or $<5 \mathrm{~mm}$ ), ${ }^{\mathrm{S}+}$ High sensitivity to antibiotic or plant extract, J. montana=J asonia montana, $\mathrm{DIZ}=$ Diameter of inhibition zones, S. aureus=Staphylococcus aureus, CNS=Coagulase-negative Staphylococci, S. agalactiae $=$ Streptococcus agalactiae, $\mathrm{E}$. coli=Escherichia coli, A. herb alba=Artemisia herb alba, SD=Standard deviation

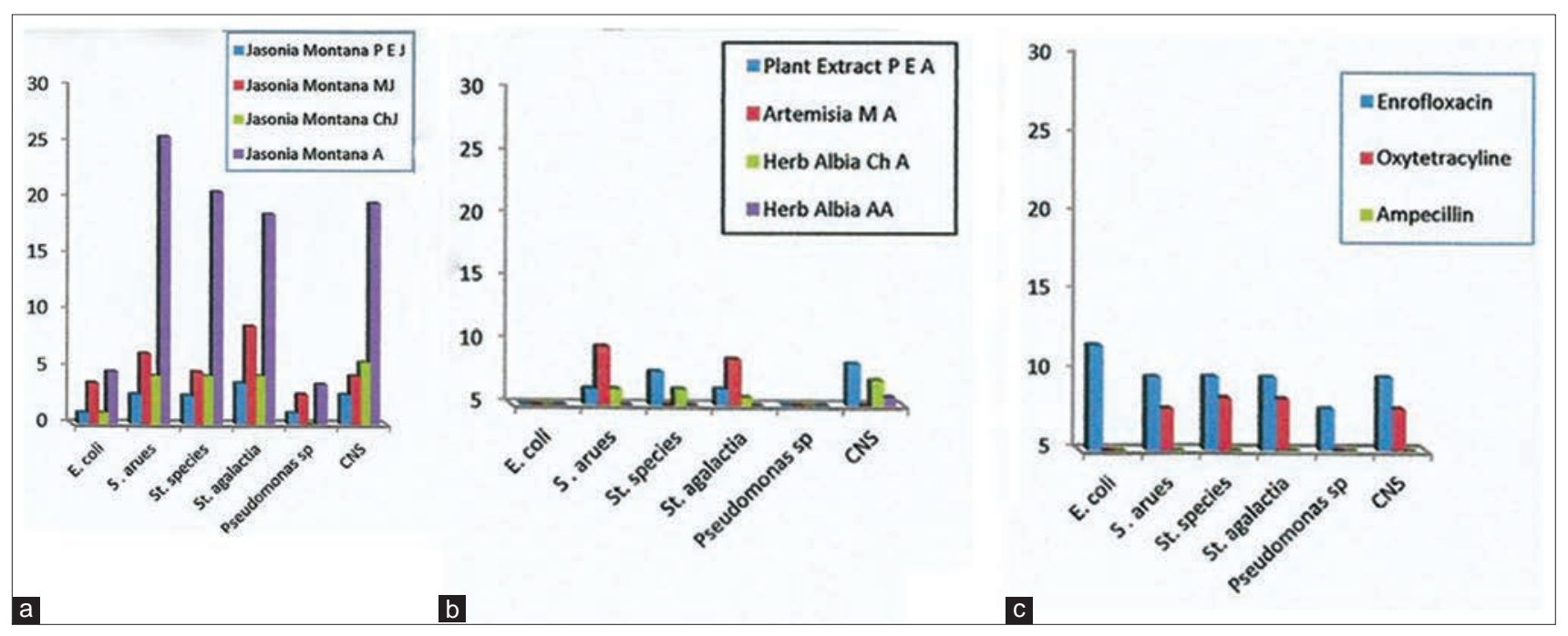

Figure-3: (a) Revealed that the Jasonia montana plant acetone extract showed the highest antibacterial effect on Staphylococcus aureus, Streptococcus ssp. and coagulase-negative Staphylococci, other extracts have antibacterial effect on the same bacteria but still lower than acetone extract. (b) the Artemisia herb alba had moderate effect on Gram-positive bacteria, (c) antibiotic showed antibacterial effect on Gram-negative and Gram-positive bacteria.

economic losses in dairy cows and bio health hazard to human worldwide especially in developing countries as in Egypt [31,32]. The present study showed clearly that uses of clinical inspection and CMT examination were provided efficient diagnostic tool for detection and differential of clinical and subclinical mastitis and apparently normal health cattle and this observation is in agreement with Gianneechini et al. [33]. They found that the screening of clinical and subclinical mastitis in animals by CMT is still the superior diagnostic tool. The high prevalence of subclinical mastitis in dairy cattle may be due poor hygiene and poor management in rural areas which the small or individuals dairy unit owners have no concept of subclinical mastitis, teat dipping, dry cow treatment and usually do not keep adequate herd records, this explain is in agreement with Fadlelmoula et al. [34] On the other hand, this explain is disagreement with El-Attar et al. [35]. Isolation of the causative organisms by culturing is considered the most suitable, accurate 


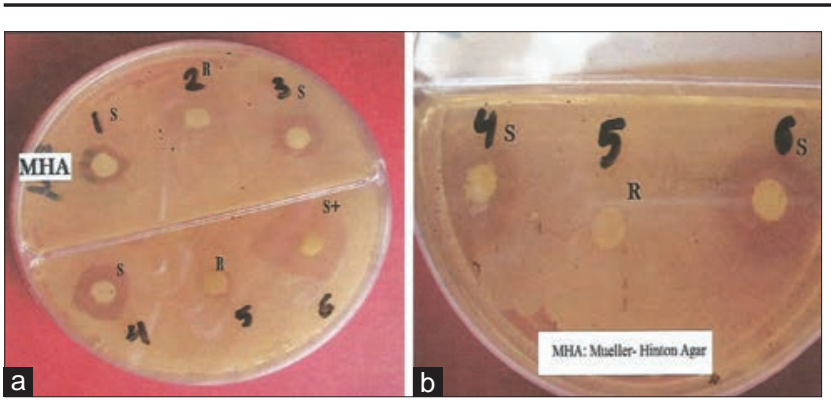

Figure-4: Antimicrobial activity of plant extracts on bacteria isolated from bovine mastitis by disk diffusion method (a) $(1,3,4$ and 6$)$ inhibition around the discs or resistant (R) as in (2 and 5) no inhibition zone around the desk. (b) susceptible (S) as in (4 and 6) or resistant (R) as in (5).

and reliable method for identification of the causative agent [36,37]. Out of these 203 milk samples, a total of 148 different bacterial isolates were recovered, they were identified by biochemical test and found the isolated bacteria belonging to eight species as in Table-2 and Figure-2. These results were in agreement with many authors $[38,39]$. They are considered the culturing of bacterial is a gold standard method. The highest prevalent of E. coli, S. aureus and S. agalactiae may be due to transmission by teat-to-teat or cow-to-cow spread, possibly via by the Milker's hands under the lack of hygiene, these finding were in agreement with Das et al. [38], who considered these microorganisms as major etiological agents of clinical and subclinical mastitis worldwide. The other bacterial species isolated in the present study CNS, S. dysgalactia, Pasteurella spp., Pseudomonas spp., Klebsiella spp. are a minor causes of bovine mastitis [40]. Many of these bacteria isolated from bovine mastitis are also the causative agents of human diseases i.e. E. coli, $S$. aureus and $S$. agalactiae and higher incidence rate of $E$. coli may be due to poor hygienic conditions of the environment as $E$. coli infects the udder via teat canal from the environment. S. aureus is causing food poisoning and frequently found in milk come from dairy cattle with mastitis [7].

Many authors have recorded an increase in the drug resistance bacteria isolated from bovine mastitis [40]. Antibiotics sensitivity test is important to suggest suitable antibacterial treatment to prevent antibiotic resistance, potential health risk for humans. The obtained results in Table- 3 and Figure- 3 and 4 showed clearly that the penicillin, ampicillin and oxtetracycline were found to be less effective against bacteria isolate from bovine mastitis may be due to increased indiscriminate and frequent use of those antibiotic in dairy animals leading to develop of antibiotic resistance bacteria which necessitates develop and search for novel sources as antimicrobial agents. Medicinal plant-derived compounds have increased widespread interest in the search of alternative antibacterial agents. They are safe and have a long history of use in folk medicine for the treatment of infectious diseases [41]. According to the World Health Organization, medicinal plants would be the best source to obtain a variety of drugs and active compounds. Therefore, such plants should be investigated in order to understand their properties, safety and efficiency [42]. The aim of the current study was to evaluate the antibacterial activity of selected some Sinai medicinal plant extracts against bacteria isolated from bovine mastitis, our results in the results in Table- 3 and Figure- 4 revealed that the plant extracts by different solvent petroleum ether, methanol, chloroform and acetone exhibited a level of antibacterial activity against Gram-positive bacteria isolated from bovine mastitis. There was significant variation in the antibacterial activities of $J$. montana and A. herb alba plant extracts that have antibacterial effect against Gram-positive bacteria, the highest activity was observed with acetone extracts of J. montana compared to A. herb alba and this result is in agreement with Sampimona et al. [43]. The most effective antibacterial activity was recorded for $J$. montana showed marked level antibacterial activity against $S$. aureus, Staphylococci (CNS)and S. dysgalactia followed by $A$. herb alba were recorded and induce inhibition zone \pm SD ranged between $4.33 \pm 0.57$ and $9.67 \pm 0.57 \mathrm{~mm}$, these results were in agreement with Mothana et al. [44]. Evaluation of antibacterial activity by MIC different plant extracts of $J$. montana and A. herb alba with different solvents (methanolic, petroleum ether, acetone and chloroform)against Gram's-positive bacteria S. aureus, Staphylococci (CNS)and S. dysgalactia. The MIC value of $J$. montana acetone extract was $(1.5625 \mathrm{mg} / \mathrm{ml}$ )may be due to attributed to the rich plant contents of active components such as alkaloids and flavonoids. Also, A. herb alba plant extracts gave (50-6.25 mg/ml)against Gram's-positive bacteria particularly found to be significantly active exhibiting the little potency with all solvents used as in Table-3 and Figure-3a-c and $4 \mathrm{a}$ and $\mathrm{b}$ these results were in agreement with Sampimona et al. and Sumathi et al. [43,45]. When comparing antibacterial activities of plant extracts with enrofloxacin antibiotic against bacteria causing bovine mastitis, we found the nearly similar for inhibition patterns were recorded, and this recorded is in agreement with Sumathi et al. [45]. Finally, our results proved that the $J$. montana and A. herb alba have the ability of antibacterial activity against Grampositive bacteria isolated from bovine mastitis.

\section{Conclusion}

The present study spot highlight on isolation and identification of mastitis pathogens that are fundamental aspects of milk quality, udder health control programs and public health and food safety issues associated with food borne pathogens. CMT findings represent valuable diagnostic tools in the detection of cows with secretion disorder whose show no clinical signs of disease. Routine milk cultures should be an ongoing part of any mastitis control program. On that perspective, medicinal plants are safe, efficient and a low-cost option for treating bovine mastitis that 
should also be further explored similar to the synthetic options. Most tested plant extracts showed antibacterial activity against bacteria tested which may reflect the antibacterial activity of plant active ingredients that inhibit bacterial growth. J. montana and A. herb alba acetone extracted were possessed strong antimicrobial activities against Gram-positive bacteria isolated from bovine mastitis. All the solvents (methanolic, petroleum ether and chloroform)used in plants extraction exhibited less antibacterial activities than acetone solvent extract. Our results proved that the $J$. montana and A. herb alba plant extracts can be used as antimicrobial agent as a natural alternative manner to some of the commonly used antibiotics in human and animals but further researches is still necessary to identify active compounds, effectiveness, toxicity, safety indices and clinical trials in treatment of infectious diseases.

\section{Authors' Contributions}

GSGZ and AMA: Conception of the research idea, study design, data collection, involved with samples collection, main part of laboratory work and interpret the data and reviewed the manuscript; MEO and SA: Study design, collection of plant from Sinai, Egypt, identification of plant with group of genetics and breeding of medicinal and aromatic plants, EA: Involved with sample collection and processing of samples in the laboratory and part of laboratory work. All authors have read and approved the final revised manuscript.

\section{Acknowledgments}

The authors acknowledgment Veterinary Research Division, National Research Center, Cairo, Egypt, for providing research facilities and financial support to carry out this work.

\section{Competing I nterests} interests.

The authors declare that they have no competing

\section{References}

1. Dar, K.H., Ansari, M.M., Dar, S.H., Tantary, H.A., Baba, M.A. and Naikoo, M.U.D. (2014) Studies on subclinical mastitis in dairy cows of Jammu and Kashmir. Int. J. Vet. Med., 3: 95-99.

2. Abdel-Rady, A. and Sayed, M. (2009) Epidemiological studies on subclinical mastitis in dairy cows in Assiut Governorate. Vet. World, 2: 373-380.

3. Ahmady, M. and Kazemi, S. (2013) Detection of the enterotoxigenic genes (sei, sej) in Staphylococcus aureus isolates from bovine mastitis milk in the West Azerbaijan of Iran. Comp. Clin Pathol., 22(4): 649-654.

4. Keane, O.M., Budd, K.E., Flynn, J. and McCoy, F. (2013) Pathogen profile of clinical mastitis in Irish milk-recording herds reveals a complex aetiology. Vet. Rec., 173: 17.

5. Sudhakar, P.A., Narendra, V.K., Vikas, M.S. and Mangesh, S.M. (2009) Prevalence and current antibiogram trend of mastitic agents in Udgir and its vicinity, Maharashtra State, India. Int. J. Dairy Sci., 4: 117-122.

6. Barua, M., Prodhan, M.A.M., Islam, K., Chowdhury, S., Hasanuzzaman, M., Imtiaz, M.A. and Das, G.B. (2014)
Seasonal effects on milk yield, erythrocytic and leukocytic indices of Kankrej cattle (Bos indicus). Vet. World, 7: 483-488.

7. Mir, A.Q., Bansal, B.K. and Gupta, D.K. (2014) Subclinical mastitis in machine milked dairy farms in Punjab: prevalence, distribution of bacteria and current antibiogram. Vet. World, 7: 291-294.

8. Islam, M.A. Islam, M.Z., Islam, M.A., Rahman, M.S. and Islam. M.T. (2011) Prevalence of subclinical mastitis in dairy cows in selected areas of Bangladesh. Bangladesh $J$. Vet. Med., 9: 73-78.

9. Ahmad, I. and Aqil, F. (2007) In vitro efficacy of bioactive extracts of 15 medicinal plants against ES $\beta$ L-producing multidrug-resistant enteric bacteria. Microbiol. Res., 162: 264-275.

10. Mubarack, H.M., Doss, A. Vijayasanthi, M. and Venkataswamy, R. (2012) Antimicrobial drug susceptibility of Staphylococcus aureus from subclinical bovine mastitis in Coimbatore, Tamilnadu, South India. Vet. World, 5: 352-355.

11. Lewis, K. and Ausubel, F.M. (2006) Prospects of plant derived antibacterials. Nat. Biotechnol., 24: 1504-1507.

12. Unakal, C.G. and Kaliwal, B.B. (2010) Prevalence and antibiotic susceptibility of Staphylococcus aureus from bovine mastitis. Vet. World, 3: 65-67.

13. Lee, S.B., Cha, K.H., Kim, S.N., Altantsetseg, S., Shatar S. and Sarangerel, O. (2007) The antimicrobial activity of essential oil from Dracocephalum foetidum against pathogenic microorganisms. J. Microbiol., 45: 53-57.

14. Islam, B., Khan, S.N., Haque, I., Alam, M., Mushfiq M. and Khan, A.U. (2008) Novel anti-adherence activity of mulberry leaves: Inhibition of Streptocioccus mutans biofilm by 1-deoxynojirimycin isolated from Morus alba. $J$. Antimicrob. Chemother., 62: 751-757.

15. Somchit, M.N., Reezal, I., Nur, I.E. and Mutalib, A.R. (2003) In vitro antibacterial activity of ethanol and water extracts of Cassia alata. J. Ethnopharmacol., 84: 1-4.

16. Segal, R., Feuerstein, I., and Danin, A. (1987) Chemotypes of Artemisia herba-alba in Israel based on their sesquiterpene lactone and essential oil constitution. Phytochemistry, 15: 411-416.

17. Sarac, N. and Ugur, A. (2007) Antimicrobial activities and usage in folkloric medicine of some Lamiaceae species growing in Mugla, Turkey. Eur. Asia J. Bio Sci., 1(4): 28-34.

18. Ziyyat, A., Legssyer, A., Mekhfi, H., Dassouli, A., Serhrouchni M. and Benjelloun, W. (1997) Phytotherapy of hypertension and diabetes in oriental Morocco. $J$. Ethnopharmacol., 58: 45-54.

19. Al-Judaibi, A. and Al-Yousef, F. (2013) Effect of natural products from plant extracts on Gram-positive cocci. Proc. World Acad. Sci. Eng. Tech., 83: 315-319.

20. Ahmed, A.A., Ali, A.A. and Mabry, T.J. (1989). Flavonoid aglycones from Jasonia montana. Phytochemistry, 28: 665-667.

21. Soliman, F.M., Moussa, M.Y., Abdallah, H.M. and Othman, S.M. (2009) Cytotoxic activity of flavonoids of Jasonia montana Vahl. (Botsch) (Astraceae) growing in Egypt. Aust. J. Basic Appl. Sci., 3: 148-152.

22. Quinn, P.J., Carter, M.E., Markey, B. and Carter, G.R. (1994). Clinical Veterinary Microbiology. Wilfe Publishing, London. p95-101.

23. MacFaddin, F.J. (2000) Biochemical Tests for Identification of Medical Bacteria. $3^{\text {rd }}$ ed., Lippincott Williams and Wilkins, Philadelphia.

24. National Mastitis Council. (1999) Laboratory Handbook on Bovine Mastitis. NMC Inc., Madison, W.I.

25. AOAC. (1970) Association of Official Agriculture Chemistry. Official Methods of Analysis. $10^{\text {th }}$ ed. Association of Official Agriculture Chemistry, Washington, DC.

26. National Committee for Clinical Laboratory Standards, N.C.L.S. (2007) Performance Standards for Antimicrobial Susceptibility Testing. $10^{\text {th }}$ Informational Supplement. NCCLS Document M100-S17. Vol. 27. National Committee 
for Clinical Laboratory Standards, Wayne, PA.

27. Forbes, B.A., Sahm, D.F. and Weissfeld, A.S. (2007) Bailey and Scott's Diagnostic Microbiology. $12^{\text {th }}$ ed. Mosby Elsevier, St. Louis. 2007. p842-855.

28. Wiegand, I., Hilpert K. and Hancock, R.E.W. (2008) Agar and broth dilution methods to determine the minimal inhibitory concentration (MIC) of antimicrobial substances. Nat. Protoc., 3: 163-175.

29. National Committee for Clinical Laboratory Standards, N.C.C.L.S. (1997) Performance standard for antimicrobial disk and dilution susceptibility test for bacteria isolated from animals and humans. Approved Standard, NCCLS Document M31-A, NCCLS, Villanova, PA.

30. Petrie, A. and Watson, P. (1999) Statistics for Veterinary and Animal Science. $1^{\text {st }}$ ed. The Blackwell Science Ltd., U.K. p90-99.

31. Seleim, R.S., Rashed, A. M. and Fahmy, B.G.A. (2002) Mastitis pathogens: attachment-related virulence features, whey protein markers and antibiotic efficacy in cows. Vet. Med. J. Giza., 50: 405.

32. Elbably, M.A., Emeash, H.H. and Asmaa, N.M. (2013) Risk factors associated with mastitis occurrence in dairy herds in Beni-Suef Governorate. Worlds Vet. J., 3: 5-10.

33. Gianneechini, R., Concha, C., Rivero, R., Delucci, I. and Moreno López, J. (2002) Occurrence of clinical and sub-clinical mastitis in dairy herds in the West Littoral Region in Uruguay. Acta Vet. Scand., 43: 221-230.

34. Fadlelmoula, A., Fahr R.D., Anacker, K.G. and Swalve, H.H. (2007) The management practices associated with prevalence and risk factors of mastitis in large scale dairy farms in Thuringia-Germany 1: Environmental factors associated with prevalence of mastitis. Aust. J. Basic Appl. Sci., (4): 619-624.

35. El-Attar, A.A., Salama, M.E. and Abd El-Samie, M.M. (2002) Incidence of mastitis in lactating cows and buffaloes kept under different managemental conditions in Ismailia province. Vet. Med. J. Giza, 2: 583.

36. Abdulla, B.A., Al-Jamaly, M.M.H. and Sadoon, A.S. (2011) Isolation and identification of some bacteria causing subclinical mastitis in cows. Iraqi J. Vet. Sci., 25: 63-67.

37. Moges, N., Asfaw, Y. and Belihu, K. (2011)A cross sectional study on the prevalence of sub clinical mastitis and associated risk factors in and around Gondar, Northern Ethiopia. Int. J. Anim. Vet. Adv., 3: 455.

38. Das, K., Tiwari, S.K.R. and Shrivastav, K.D. (2010) Techniques for evaluation of medicinal plant products as antimicrobial agent: Current methods and future trends. J. Med. Plants Res., 4: 104-111.

39. Alkhamaiseh, S.I., Taher, M. and Ahmad, F. (2011) The phytochemical contents and antimicrobial activities of Malaysian Calophyllum rubiginosum. Am. J. Appl. Sci., 8: 201-205.

40. Gul, F., Shinwari, Z.K. and Afzal, I. (2012) Screening of indigenous knowledge of herbal remedies for skin diseases among local communities of North West Punjab, Pakistan. Pak. J. Bot., 44: 1609-1616.

41. Kamaraj, C., Rahuman, A.A., Siva, C., Iyappan, M. and Kirthi, A.V. (2012) Evaluation of antibacterial activity of selected medicinal plant extracts from south India against human pathogens. Asian Pac. J. Trop. Dis., 2: S296-301.

42. Wangensteen, H., Klarpås, L. Alamgir, M., Samuelsen A.B.C. and Malterud, K.E. (2013) Can scientific evidence support using Bangladeshi traditional medicinal plants in the treatment of diarrhoea? A review on seven plants. Nutrients, 5(5): $1757-1800$

43. Sampimona, O.C., Zadoksb, R.N., De Vliegherc, S., Supréc K. and Haesebrouckd, F. (2009) Performance of API Staph ID 32 and Staph-Zym for identification of coagulase negative staphylococci isolated from bovine milk samples. Vet. Microbiology., 136: 300-305.

44. Mothana, R.A.A., Gruenert, R., Bernarski, P.J. and Lindequist, U. (2009) Evaluation of the in vitro anticancer, antimicrobial and antioxidant activities of some Yemeni plants used in folk medicine. Pharmazie, 64: 260-268.

45. Sumathi, B.R., Veeregowda, B.M. and Amitha, R.G. (2008) Prevalence and antibiogram profile of bacterial isolates from clinical bovine mastitis. Vet. World, 1: 237-238. 